\title{
Sustainable Construction in Kurdish Vernacular Architecture
}

\author{
Rebaz Khoshnaw ${ }^{1 *}$ \\ 1 Department of Urban Planning and Design, Faculty of Architecture, Budapest University of Technology and Economics, \\ Múegyetem rkp. 3., H-1111 Budapest, Hungary \\ *Corresponding author, e-mail: rebaz@urb.bme.hu
}

Received: 23 October 2018, Accepted: 18 April 2019, Published online: 23 May 2019

\begin{abstract}
The Kurdistan region is currently undergoing rapid change and development in many ways. The economy is growing, and the population is increasing. Adopting a modern lifestyle is influencing individuals and social behavior. These factors are collectively affecting the architectural styles and construction techniques of the buildings. Abandoning the vernacular architecture has led to a loss of locality. This research outlines the characteristics and elements of Kurdish vernacular architecture in Erbil city and the villages in mountainous area; it then analyses them in terms of sustainability. A descriptive method is adopted to identify the sustainable aspects of traditional building techniques and designs. Finally, the paper concludes that with developed construction regulations, some of the designs and construction methods of traditional architecture, with the right management, can be adopted in modern buildings.
\end{abstract}

Keywords

Kurdistan architecture, vernacular materials, sustainable aspects, construction methods

\section{Introduction}

The environment affects human settlements differently depending on the geographical location. This can be seen and felt through the architectural patterns and lifestyle of communities. Typically, there is a predominant type of architecture, which stands out and therefore illustrates the effects of the natural environment. The materials used in the construction of buildings depend on the ease of their use as well as the needs to be met. The geographical location and the environment shape how people live in a given community at any given time, with nature affecting every facet of people's lives from food to culture and social structures. The natural environment imbues life to the entire day-to-day activities of people living in a given setting.

In different parts of Kurdistan, different architectural styles and materials can be seen. These differences are attributed to locally available materials and the geographic location. In the southern part of the region, the city of Erbil has a different climate compared with the mountainous areas in the north and northeast. Erbil area has a hot climate during the summer with a moderate winter, while the mountain villages have cold to extremely cold winters with moderate summers.

This paper identifies the push factors that have inspired specific forms of construction and architecture in the given areas. The article will cover various aspects of traditional features and review the difference in the designs. It will also discuss the different types of construction materials and house typology in Kurdistan.

Modernity is taking root in different parts of Kurdistan, threatening the existence of traditional design. It is therefore imperative to understand the history and topography of Kurdistan to help solve the different problems that have since developed. The advantages derived from vernacular architecture help in understanding the benefits and comfort that come with adapting to the climate. The paper focuses on the different construction designs in Kurdistan, and questions which characteristics and elements made the vernacular architecture of Kurdistan compatible with the aspects of sustainability, and how this can be adopted into modern designs.

\section{Landscape and Environment of Kurdistan}

Greater Kurdistan is the geographic region inhabited by Kurds. It consists of a plateau and mountainous areas. Greater Kurdistan is spread over parts of what are now south-east Turkey, northern Iraq, western Iran and a smaller part of northern Syria (Fig. 1). The Kurdistan Region of Iraq stretches through the mountains and uphills to the fertile plains of Iraq (Fig. 2). Kifri is the lowest part of the region since it is only 140 meters above sea level, with the peak of 


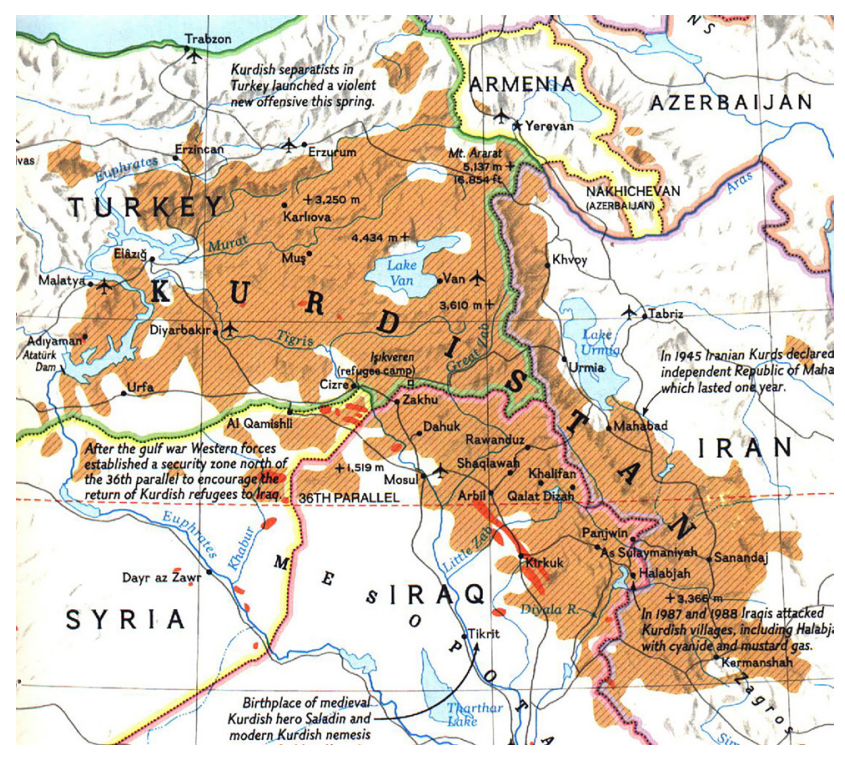

Fig. 1 Kurdistan, Kurdish inhabited areas (Source: Oriental Review)

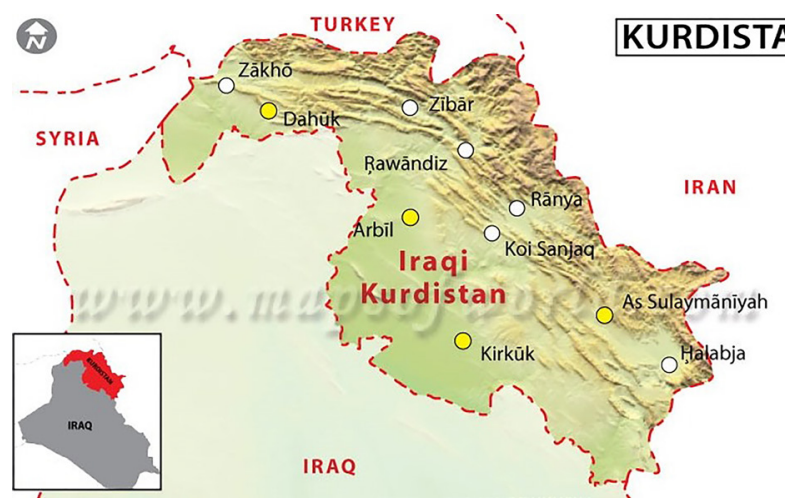

Fig. 2 Kurdistan Region of Iraq (Source: RIEAS)

Hasarost Mountain in Erbil the highest point at 3,607 meters above sea level (Aziz, 2003). The north-northeastern area is occupied by the Zagros Mountains with higher altitudes covered by snow throughout the winter and vegetation that ranges from grass to a huge array of forests.

The region has a latitude of 3300 North and longitude of 4400 East. The average temperatures in winter are between $2-13{ }^{\circ} \mathrm{C}$, reaching below freezing in mountainous areas, and $39-43{ }^{\circ} \mathrm{C}$ in summer (KRG). Consequently, the Kurdistan region can be divided into two geographic and climatic zones; the mountain ranges with cold and snowy winters, and the area around Erbil, characterised by plains and high summer temperatures.

\section{Historical Background of Erbil City}

The city of Erbil has been home to numerous civilisations throughout the history of the country and is a significant cultural heritage site. Erbil Citadel (Fig. 3) is the historical city center and its inscription on the World Heritage list

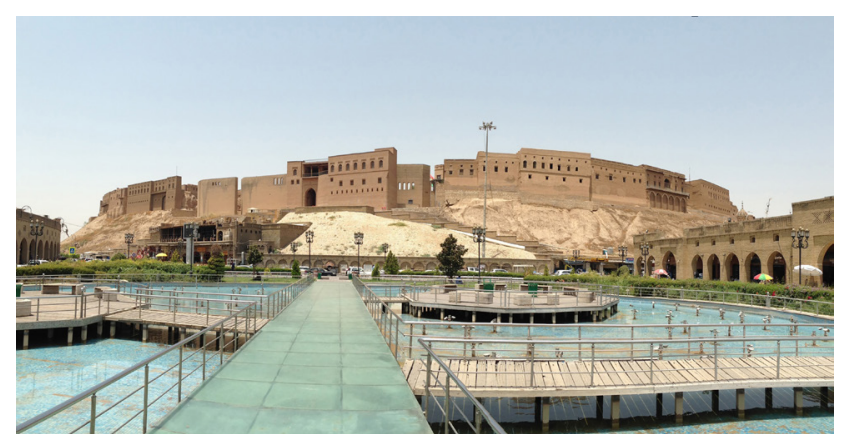

Fig. 3 Erbil Citadel (Source: Author, 2018)

in 2014 marks its historical past. The city is one of the oldest inhabited cities in the world. The city was occupied as early as 6000 years BCE with evidence of settlement from the inhabitant's activities and in the caves in the mountainous regions (Morris, 2008). The city of Erbil was pronounced a governorate in 1923.

Erbil Citadel is located on a 32-meter mound or tell that visually dominates the city. It is a roughly oval shaped town within in the city and is made up of conventional courtyard houses built from fired bricks. Erbil Citadel is an epitome of the unique sample of towns that nestle in the prestigious and central parts of the city. This has attracted many people, and it has since developed into a cultural heritage haven for traditional housing. The Citadel is a testament to its immensely rich culture.

\section{Historical Development of Settlements in Kurdistan}

Kurdistan was home to some of the earliest forms of civilisations. As a cradle for early human beings, the traditional housing developed in three stages from the cave stage to the commuting stage and lastly settlement stage. The cave stage is the period when the earliest inhabitants of the mountainous regions lived in caves to protect themselves from harsh climatic conditions. Kurdistan boasts numerous such caves, with Shanidar Cave (Figs. 4, 5) an excellent example. The commuting stage involved the temporary relocations that the earliest inhabitants made during the change of seasons in a nomadic lifestyle. People, during this time, began erecting homes to live in, which eventually resulted in the joint communities we see today (Braidwood and Howe, 1960). The settlement stage marked the start of today's structures in the mountainous regions.

The typical architectural designs in Kurdistan are characterised by the efficient utilisation of resources that are available to hand. The communities that occupied the area in early times formed their communities based on shared activities and authority (Braidwood and Howe, 1960). 


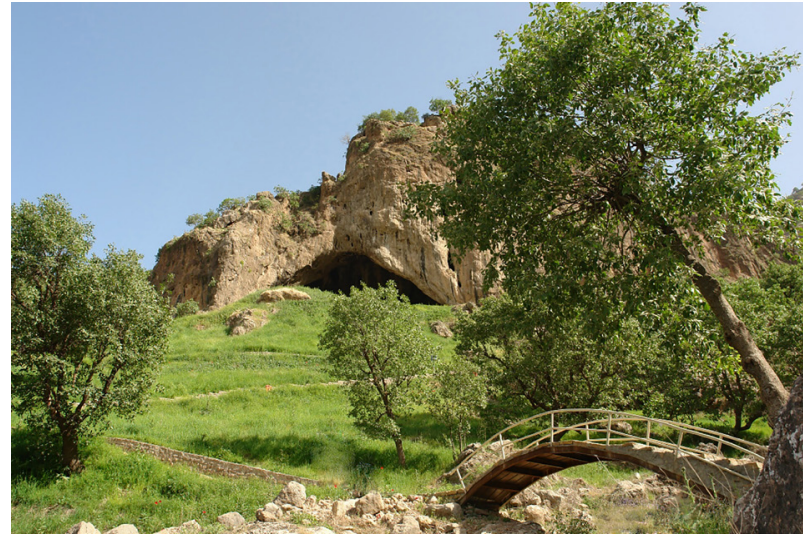

Fig. 4 Shanidar Cave (Source: General Board of Tourism of Kurdistan - Iraq)

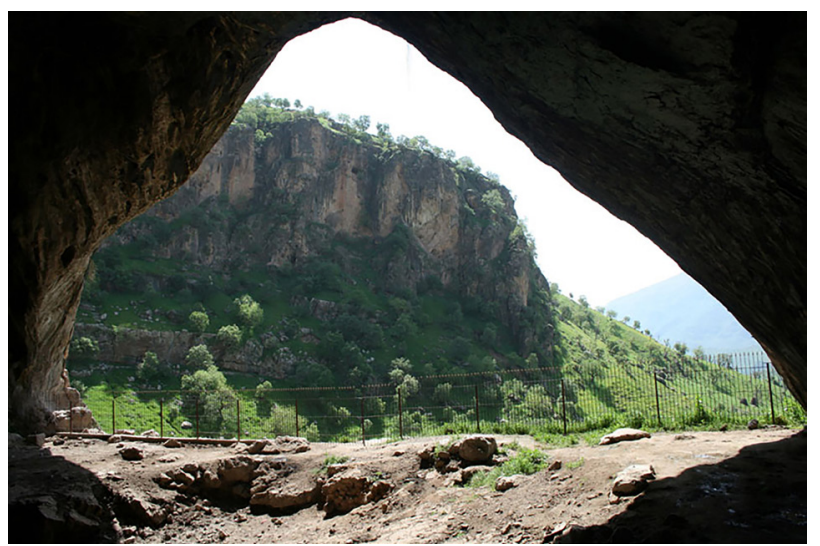

Fig. 5 Shanidar Cave (Source: General Board of Tourism of Kurdistan - Iraq)

\section{Sustainable Design}

Sustainable design in architecture refers both to the act of ensuring a comfortable and healthy environment for the occupants of different areas as well as the structures. The key components of sustainable architecture in Kurdistan need to be protected. Oliver (1997) noted that the success of conventional architecture lies within a framework of logical responses and resources that are available in the environment. Additionally, factors such as climate and the needs of society affect the structure.

Passive Solar Design: One of the crucial aspects of sustainable architecture is passive solar design. Passive solar design reduces energy consumption through techniques that are based on natural resources. To take full advantage of solar energy and create comfortable microclimate conditions, factors such as design and orientation should be considered (Owens, 1992). Vegetation and water bodies are other factors in passive design that help achieve a sustainable environment by evaporative cooling processes on building surfaces and open spaces.
Greening: we can embrace and bring nature into the lives of residents through a diversity of greening and open landscaping (Elkin et al., 1991). Greening enhances the quality of air and positively contributes to biodiversity. In most hot and dry climates, greening is a vital to moderate the microclimate of open courtyards; the traditional open courtyard houses in Erbil are a clear example of this.

Building Materials: the types of building materials are another crucial aspect of sustainability. The vernacular building materials are considered as renewable resources and environmentally friendly. In the Kurdistan region, the traditional building materials are stone, wood and fired bricks (Fig. 6).

These materials can conserve energy and improve occupant health. The evaluating characteristics for green building materials are recycled content, zero or low toxicity, rapidly renewable materials, zero or low harmful gas emissions and local productivity (Howe et al., 2010). The benefits of using local materials in term of sustainability are as follows:

1. The community manages the materials used in a way that does not negatively impact the environment and avoids the depletion of resources.

2. Materials are renewable resources, and the method of their extraction does not affect the local ecosystem.

3. Besides saving transportation and costs, local materials reduce the waste and pollution produced by the large equipment used in transportation and construction.

\section{The Vernacular Concept}

Frank Lloyd Wright described vernacular architecture as the buildings that people had built as a response to their actual and environmental needs concerning their culture, society, economy, and way of life.

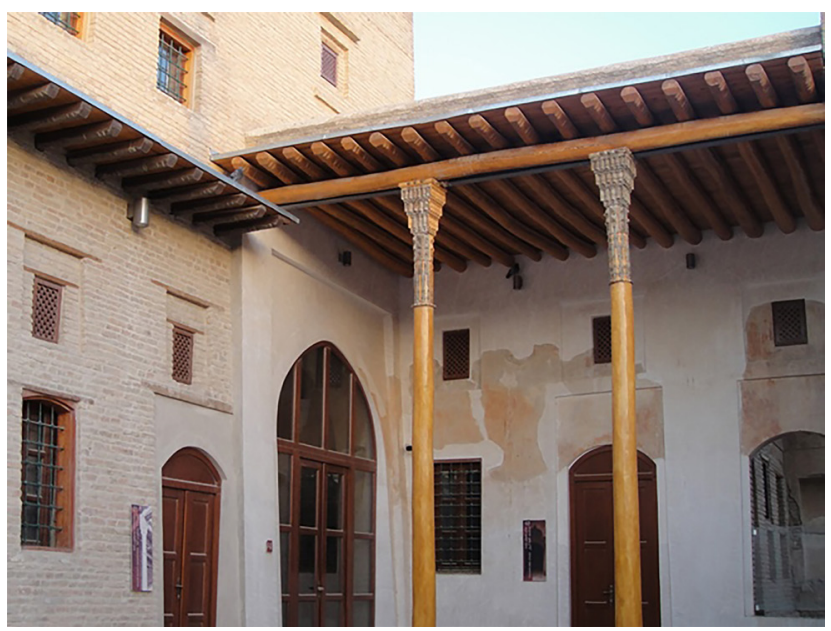

Fig. 6 A House in Erbil citadel with traditional building materials (Source: Author, 2018) 
Oliver (1997) refers to vernacular architecture as one that entails the whole facet of dwellings and other buildings of the people. The idea is related to the differing environmental situation that a specific region faces and the availability of resources. These are then adapted by utilizing traditional technologies and tailor-made to suit the community. He also states that every other form of vernacular architecture is designed to meet certain needs and the cultures that result in those needs.

Vernacular architecture is then merely a generalised form of folk architecture (Steele, 1988). More often than not it may be seen as the use of design dependent on the different climate, culture, and materials of the specific region.

\subsection{Vernacular Architecture in Erbil}

The forms of the buildings and houses are characterised by colors, patterns and different climatic conditions. Sunlight is trapped and used in unique house designs by the contour layout as well as by the house windows. The geography around the inception of vernacular architecture is comprehensively explained by Izady (1992), who noted that the Kurds, with their history, have resulted in the continuous evolution and integration of a new people into Kurdistan, which is their homeland.

Vernacular architecture in Kurdistan is compatible with sustainability in many aspects. Sustainable living in Kurdistan is achieved through the proper adherence to the given methods of curbing heat loss as well as adapting environmentally friendly factors.

The traditional buildings of Erbil are surrounded by high walls with open courtyards (Figs. 7, 8). Windows are arranged in specific directions. Additionally, the spaces in the buildings are situated in particular areas to allow for ventilation since the city is in a hot and arid climate.

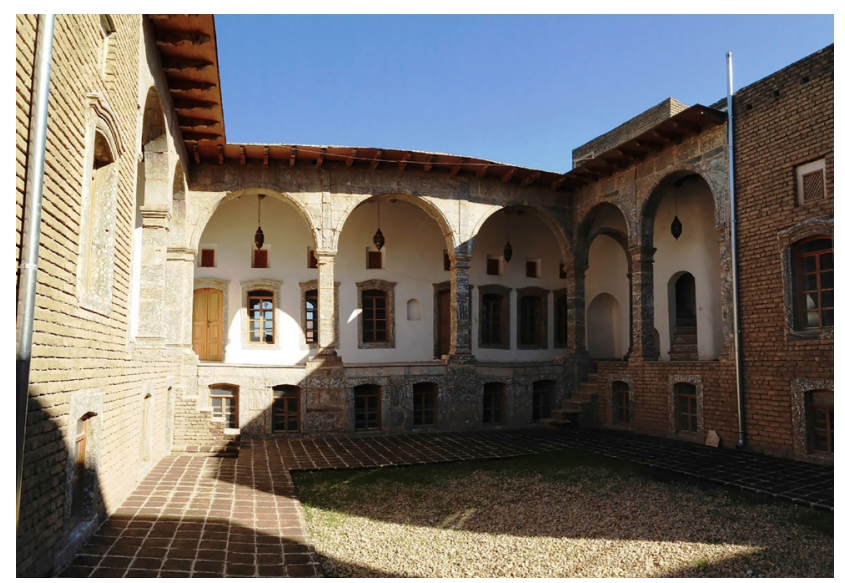

Fig. 7 Traditional design of Erbil's buildings (Source: Author, 2013)

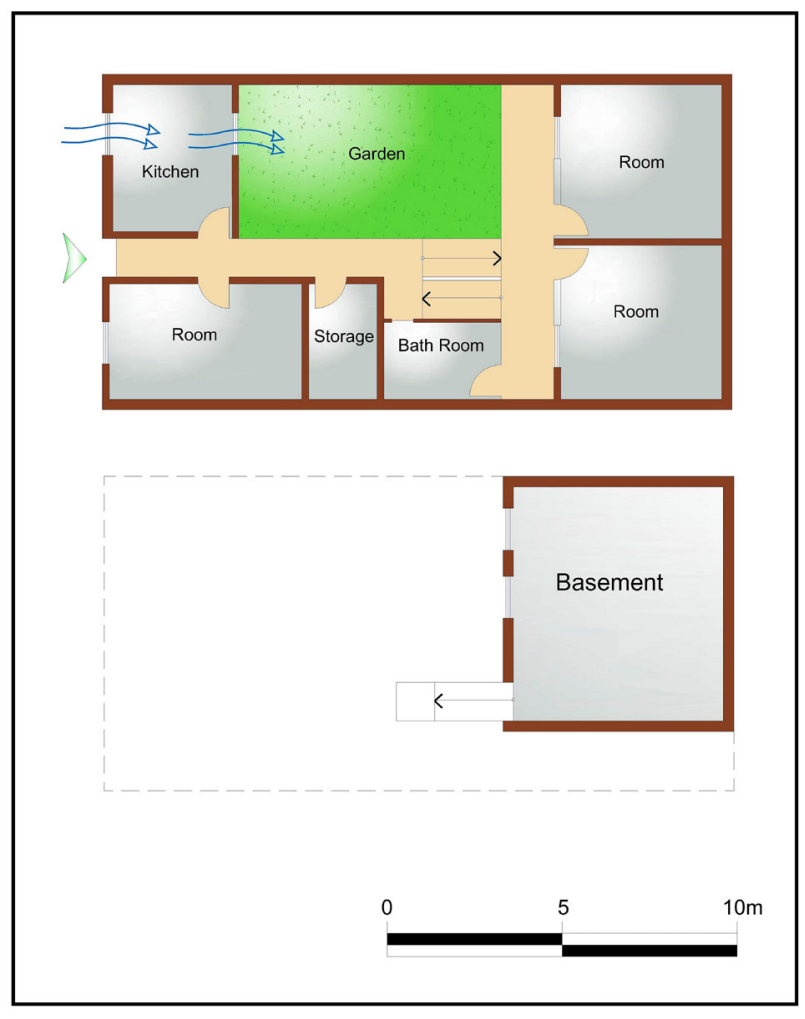

Fig. 8 Traditional design of Erbil's buildings (Source: Author)

Most of the houses in Erbil Citadel consist of only two floors. The basement is beneath the courtyard at a depth of 1 to 1.5 meters and can only be accessed easily from the courtyard (Fig. 9). These lower floors were usually vaulted ceilings (Fig. 10).

The courtyards play a crucial role in achieving the building's objectives:

1. The purpose of open courtyards is to avoid hot or cold air currents by always planting and shading.

2. The courtyards raise the dynamic air movement, increase shaded areas and reduce thermal loads. Additionally, the inclusion of plants and water inside increases the effectiveness of these courtyards to provide the required level of comfort.

3. Provide space for socialising and family time It could be said that healthy living promotes a healthy life and sustainability.

The natural air movement depends on two principles:

- The first principle depends on the variation in air pressure caused by variations in wind speed, and leads to the flow of air from high pressure to low-pressure areas.

- The second principle depends on air movement by affecting load - the chimney effect. The chimney effect is when warm air rises and is replaced by cooler air. 


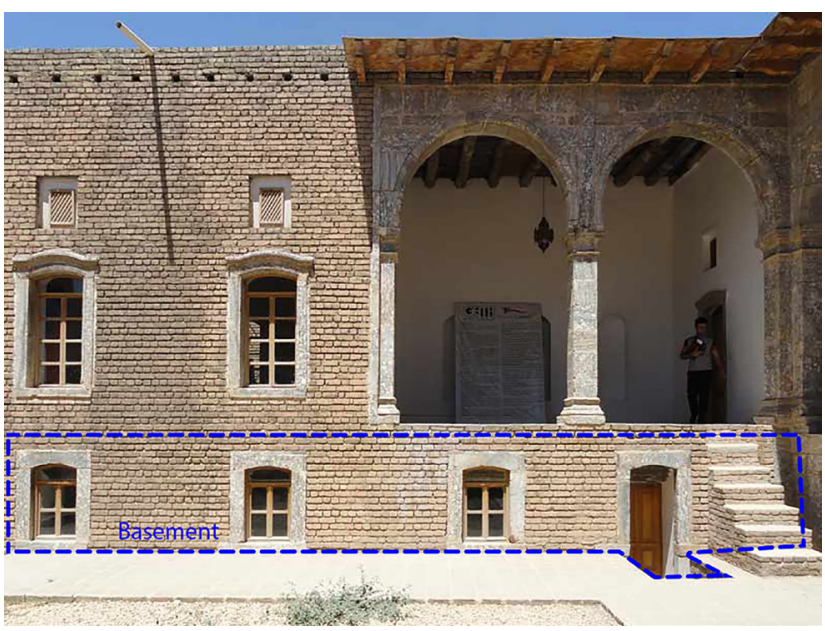

Fig. 9 A traditional design of Erbil's buildings (Source: UNESCO, Modified by the Author)

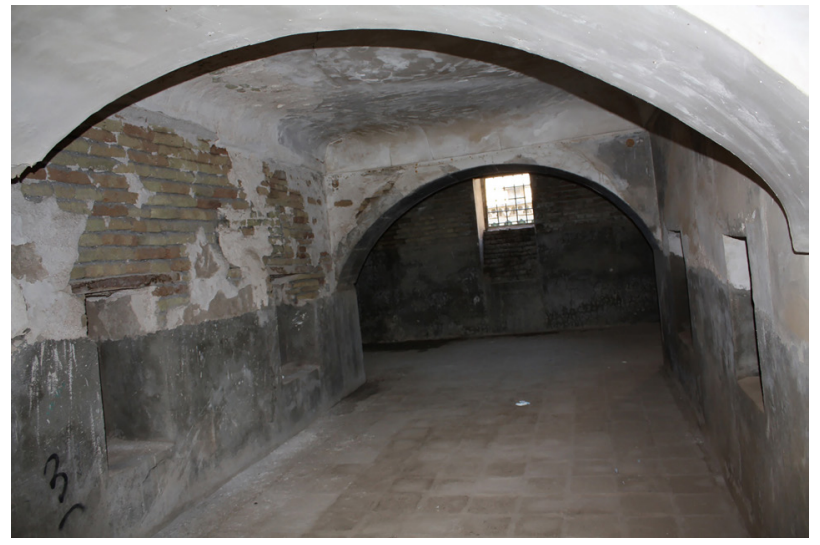

Fig. 10 Basement ceiling in a Citadel house (Source: Author, 2013)

The basements in Erbil Citadel are essentially cellars used for cooling purposes. Another essential element is Shanashel (Fig. 11), which act as extensions to the buildings; this form of construction is primarily to light the houses. They are conventionally designed to control airflow in the building, reduce incoming air temperature, as well as provide privacy. The first floor is comprised of a rectangular yard surrounded by rooms, and a second floor with connected rooms that gave access to ventilation and other openings (Fig. 8).

The materials that were used in the construction of the designs were mud, gypsum and other materials that were easily accessible. In addition, they used fired bricks in construction as a bid to adapt to the hot conditions of the area.

\subsection{Kurdish Vernacular Architecture in Mountainous Areas}

It is essential to consider the effects that environment has on house design. Construction of any form of building in cold areas will be based on the correct location of the

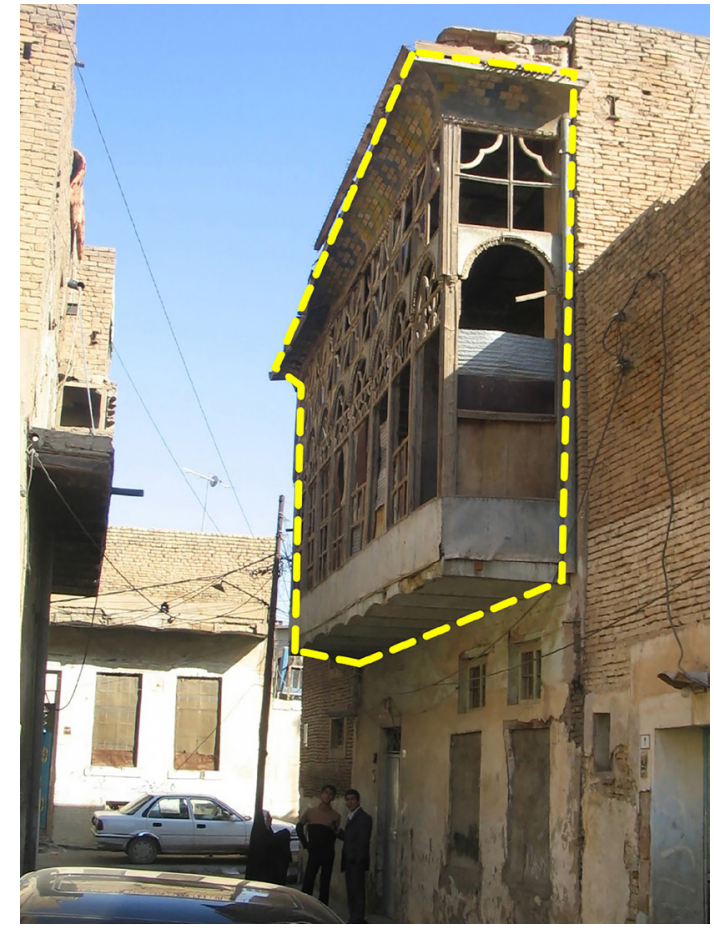

Fig. 11 Shanashel (Source: Ministry of Municipalities_KRG, Modified by the Author)

building. The layout should be based on heating and solar irradiation. Hence, the direction of the buildings plays a vital role in the design.

According to the study carried out by Habitat (2001), houses were constructed facing south to receive the maximum amount of sunlight. This is an adaptive feature that is used in cold mountainous climates. Windows of these houses are very small to prevent any form of heat loss. Houses in the mountainous areas are arranged in specific terraces to ensure the interdependency of each household on the other (Habitat, 2001). Also, their structure is in the form of a stairway to overcome the contour layout problems (Fig. 12). In these villages, stone buildings prevail (Figs. 13, 14).

It is an easily available material and offers a protective environment for the inhabitants since the region is prone to strong winds, rain and heavy snow (Fig. 15). For roofs, timber frameworks are used, covered with layers of mud and straw.

\section{Building Materials and Modernity in Kurdistan}

Modernity according to Berman (1982), refers to the perpetual change and transformation that affects every facet of knowledge in life. The impact of modernity and globalisation has many implications for the development of some settlement types in this area. 


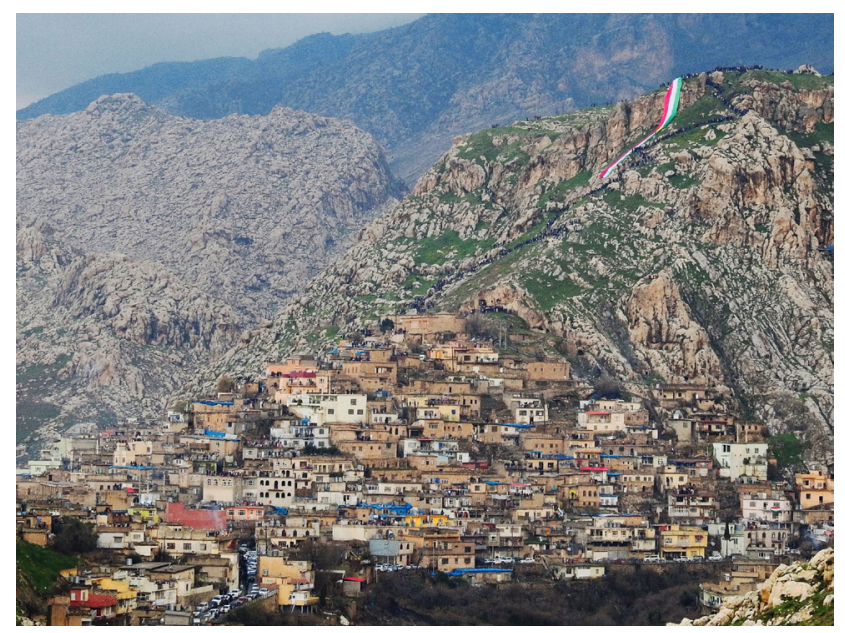

Fig. 12 Kurdish town of Akre (Source: Wikimedia)

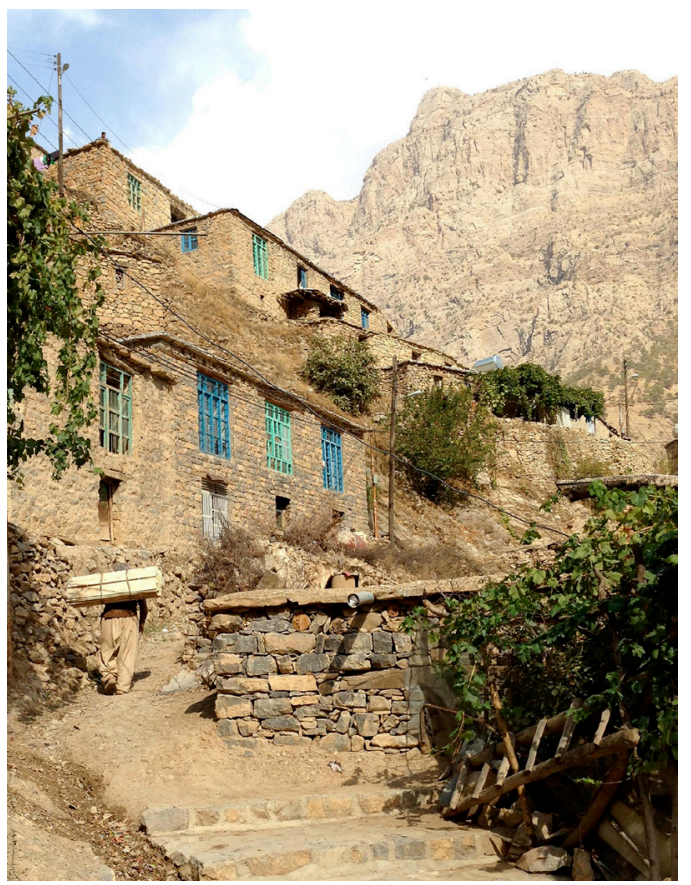

Fig. 13 Stone buildings in Belbar village. Photo courtesy of Michael Chow. (Source: Chow, 2013a)

Houses construction in Kurdistan has evolved since the prehistoric era, together with building techniques. The traditional designs in cities consisted of interior courtyards that gave the rooms a sense of security and thermal comfort. The use of bricks in the construction of buildings helped them adapt to the hot weather in urban settings.

The arrival of the British in the early $20^{\text {th }}$ century gave rise to the use of different materials for construction (Braidwood et al., 1983). Materials such as cement and iron were used during the inception of the new era (Al-Taie et al., 2012). People tried to apply British designs and ideas; this period marked the rise of the urban cities of

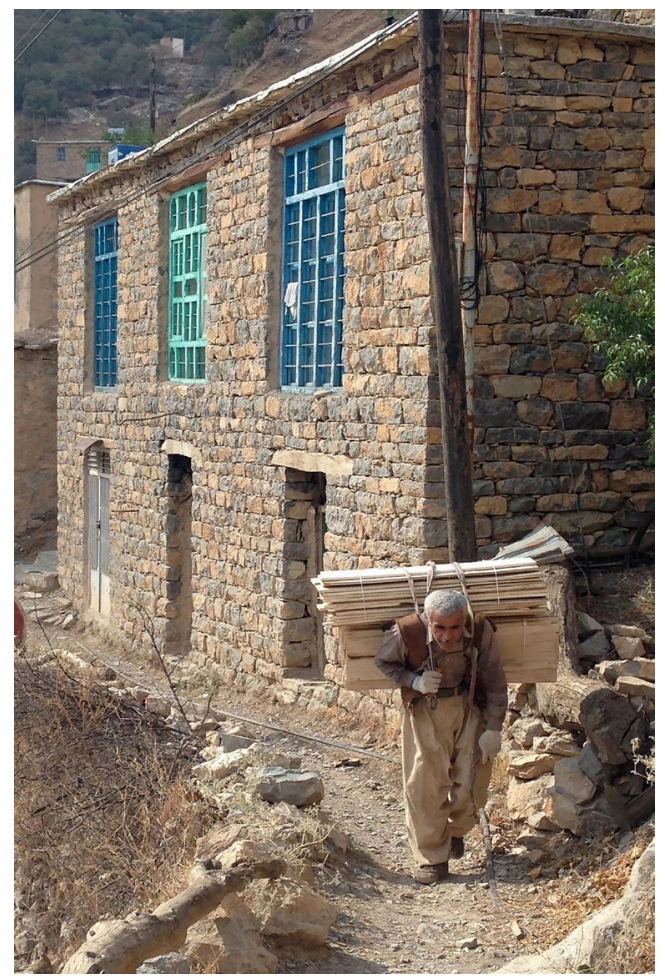

Fig. 14 Stone buildings in Belbar village. Photo courtesy of Michael Chow. (Source: Chow, 2013b)

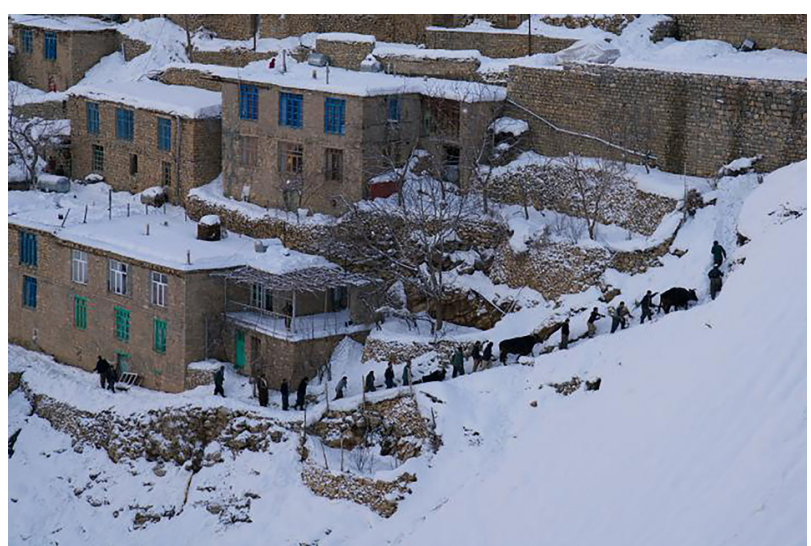

Fig. 15 The harsh winter in mountainous villages (Source: Qantara.de)

Kurdistan. The new districts of the city of Erbil are characterised by steel and concrete since the abolition of local building materials such as bricks and stone. Steel and concrete do not conform to the region's climatic conditions; this has resulted in insufficient open spaces for different activities that the traditional design and structures supported. This has also contributed to the rising temperatures of the city's atmosphere. In the past, houses used to revel in their well-moderated structures that helped to control and regulate the climate. Urban environments were more bearable compared to the current state, which does not promote the green culture of conventional architecture. 
In general, the rise of technology has forced people to develop structures to suit them but do not match the environment. Technology has resulted in a less economic use of materials in the region and subsequently, greater costs. The conventional models were suited for protection against the harsh climatic conditions; however, increasing globalisation in the use of alternative materials has affected the region negatively (Shareef, 2014).

\section{Conclusion}

The environment impacts the general rhythm, style and lifestyle of the people in a given community. Nature interacts with every part of our lives; consequently, it is not possible to separate from its influence. The natural environment affects both the people in urban settings as well as those in rural situations since those in the mountainous regions are isolated from the urban. The techniques, materials, and topography of these regions affect the daily operations of the people.

The trends and patterns of western lifestyles resulted in changes that are being seen in the cities and mountainous

\section{References}

Al-Taie, E., Al-Ansari, N., Knutsson, S. (2012) "The Progress of Buildings Style and Materials from the Ottoman and British Occupations of Iraq", Journal of Earth Sciences and Geotechnical Engineering, 2(2), pp. 39-49.

Aziz, M. (2003) "Agrometeorology in Kurdistan of Iraq: a contemporary history", INSAM (The International Society for Agricultural Meteorology) [online] Available at: http://www.agrometeorology. org/topics/history-of-agrometeorology/agrometeorology-in-kurdistan-of-iraq-a-contemporary-history [Accessed: 18 September 2018]

Berman, M. (1982) "All That Is Solid Melts into Air", 2nd ed., Penguin Books, New York, USA.

Braidwood, L. S., Braidwood, R. J., Howe, B., Reed, C. A., Watson, P. J. (1983) "Prehistoric Archeology Along the Zagros Flanks", 2nd ed., The Oriental Institute of the University of Chicago, Chicago, USA. [online] Available at: https://oi.uchicago.edu/ research/publications/oip/prehistoric-archeology-along-zagros-flanks [Accessed: 18 September 2018]

Braidwood, R. J., Howe, B. (1960) "Prehistoric Investigations in Iraqi Kurdistan", 1st ed., The Oriental Institute of the University of Chicago, Chicago, USA. [online] Available at: https://oi.uchicago. edu/research/publications/saoc/saoc-31-prehistoric-investigations-iraqi-kurdistan [Accessed: 18 September 2018]

Chow, M. (2013a) "Belbar", [online] Available at: http://www.ipernity. com/doc/michael.chow/28805113/in/album/578709 [Accessed: 20 September 2018]

Chow, M. (2013b) "Belbar", [online] Available at: http://www.ipernity. com/doc/michael.chow/28805213/in/album/578709 [Accessed: 20 September 2018]

Elkin, T., MacLaren, D., Hillman, M. (1991) "Reviving the City: towards sustainable urban development", 1st ed., Friends of the Earth, London, UK. areas. The region has adopted new western cultures that do not conform to the environmental settings of the area. The implementation of western culture in conventional regions can only work against the environment. This needs to be dealt with by the architects, researchers and the municipality's decision makers. Adopting the traditional settings and techniques of house construction in Kurdistan helps in curbing the problems widespread in the region.

The abandonment of the conventional, traditional methods of house design has resulted in changing construction designs and materials in the region. These changes were more of needs rather than a luxury. The cultural heritage that is tapped from the traditional typology of house design is invaluable; adopting the design concepts of vernacular architecture into modern strategies is both possible and desirable. Furthermore, with the population increase in the region, housing needs are growing at a high rate. Thus, it is of paramount importance to develop design and construction regulations in the region that complement the issues.

General Board of Tourism of Kurdistan - Iraq "Shanidar Cave", [online] Available at: http://bot.gov.krd/erbil-province-mirgasor/history-and-heritage/shanidar-cave [Accessed: 02 July 2018]

Habitat (2001) "Learning from tradition to improve housing design", United Nations Human Settlements Programme (Habitat), Settlements Rehabilitation Programme - Northern Iraq, Duty station: Erbil, Iraq, Homestead Typological Analysis Report. [online] Available at: https://www.humanitarianlibrary.org/resource/learning-tradition-improve-housing-design-0 [Accessed: 21 September 2018]

Howe, J. C., Gerrard, M. B., Fucci, F. R. (2010) "The Law of Green Buildings: Regulatory and Legal Issues in Design, Construction, Operations, and Financing", 1st ed., American Bar Association, Chicago, USA.

Izady, M. (1992) "The Kurds", 1st ed., Crane Russak, Washington, D.C., USA.

KRG (Kurdistan Regional Government) "Kurdistan's geography and climate", [online] Available at: http://cabinet.gov.krd/p/page.aspx$? 1=12 \& \mathrm{~s}=050000 \& \mathrm{r}=303 \& \mathrm{p}=213$ [Accessed: 05 July 2018]

Ministry of Municipalities_KRG (2009) "Erbil Master Plan Report_2009", Documents Collection, the Archive of General Directorate of Urban Planning, Erbil, Iraq.

Morris, A. E. J. (2008) "History of Urban Form: Before the Industrial Revolutions", 3rd ed., Longman, New York, USA.

Oliver, P. (1997) "Encyclopedia of Vernacular Architecture of the World", 1st ed., Cambridge University Press, Cambridge, New York, USA.

Oriental Review (2015) "Map of Kurdistan", Open Dialogue Research Journal, [online] Available at: https:/orientalreview. org/2015/08/10/strategic-scenarios-surrounding-prolonged-kurdish-insurgency-in-turkey-i/ [Accessed: 15 October 2018] 
Owens, S. (1992) "Energy, environmental sustainability and land-use planning", In: Michael Breheny (ed.) Sustainable Development and Urban Form, 1st ed., Piton, London, UK, pp. 79-105.

Qantara.de "The festival of Pir Shalyar", [online] Available at: https://en.qantara.de/content/the-festival-of-pir-shalyar [Accessed: 15 October 2018]

RIEAS (Research Institute for European and American Studies) (2014) "Kurdistan", [online] Available at: http://www.rieas.gr/researchareas/editorial?start=168 [Accessed: 15 October 2018]

Shareef, Y. (2014) " tarikh fn ala'marah ala'rakiah fi mkhtlf ala'sour" (History of Iraqi Architecture in Various Ages), 1st ed., Arab Institute for Research \& Publishing, Beirut, Lebanon. (in Arabic)
Steele, J. (1988) "Hassan Fathy (Architectural Monographs No 13)", 1st ed., St. Martins Press, New York, USA.

UNESCO "Erbil Citadel (Iraq)", [online] Available at: http://www.unesco.org/new/en/media-services/multimedia/photos/photos-forthe-new-inscriptions-2014/iraq/ [Accessed: 05 July 2018]

Wikimedia "Akre city", [online] Available at: https://commons.wikimedia.org/wiki/File:Akre_city.jpg [Accessed: 05 July 2018] 